\title{
IMPLEMENTATION OF SCALAR CONTROL METHOD FOR 3 PHASE INDUCTION MOTOR SPEED CONTROL
}

\author{
Abdul Muis Prasetia ${ }^{1}$ \& Hadi Santoso ${ }^{2}$ \\ ${ }^{1,2}$ Universitas Borneo Tarakan \\ E-mail: prasetia.electric@gmail.com
}

\begin{abstract}
This paper presents design and implementation of scalar control for 3 phase induction motor. This method leads to be able to adjust the speed of the motor by control the frequency and amplitude of the stator voltage of 3 phase induction motor, the ratio of stator voltage to frequency should be kept constant, which is called as V/F or scalar control of 3 phase induction motor drive. The proposed control system is used to generate control signals to overcome the nonlinear dynamics of 3 phase induction motor. Simulation results show that the 3 phase induction motor is able to track the frequency input shift via inverter with $50 \mathrm{~Hz}$ frequency get speed $2090.8 \mathrm{rpm}$.
\end{abstract}

Keywords: scalar control; 3 phase; speed control; frequency; induction motor

\begin{abstract}
ABSTRAK
Makalah ini menyajikan desain dan implementasi kontrol skalar untuk motor induksi 3 fasa. Metode ini dapat menyesuaikan kecepatan motor melalui pengendalian frekuensi dan amplitudo tegangan stator motor induksi 3 fasa, rasio tegangan stator terhadap frekuensi harus dijaga konstan, yang disebut sebagai kontrol V/F atau kontrol skalar motor induksi 3 fasa. Sistem kontrol yang diusulkan digunakan untuk menghasilkan sinyal kontrol yang dapat mengatasi dinamika nonlinier motor induksi 3 fasa. Hasil simulasi menunjukkan bahwa induksi motor induksi 3 fasa mampu melacak pergeseran masukan frekuensi via inverter dengan frekuensi $50 \mathrm{~Hz}$ mendapatkan kecepatan 2090,8 rpm.
\end{abstract}

Kata kunci: kontrol skalar, 3 fasa, kontrol kecepatan, frekuensi, motor induksi

\section{PENDAHULUAN}

Dewasa ini fungsi motor listrik sudah banyak diterapkan dalam kehidupan. Baik untuk rumah tangga, industri, transportasi dan lain-lain. Motor listrik yang digunakan terbagi dua jenis berdasarkan sumber tegangannya yaitu motor Direct Current (DC) dan motor Alternating Current (AC) ${ }^{(1)}$. Pada mulanya motor DC lebih banyak digunakan pada aplikasi yang membutuhkan pengaturan kecepatan dan torsi, karena fluks dan torsi motor DC dapat dengan mudah diatur, yaitu dengan mengubah arus medan atau arus jangkarnya. Disamping itu tidak memerlukan konverter untuk melakukan pengaturan kecepatan dan torsi pada motor $D^{(2)}$. Namun motor DC membutuhkan perawatan yang intensif karena memiliki komutator dan sikat arang (brush), ini menyebabkan sistem kurang handal (reliable), selain itu harganya relatif lebih mahal jika dibandingkan dengan motor induksi $^{(3,4)}$.

Konstruksi motor induksi lebih sederhana dibandingkan dengan motor DC, tidak ada bagian stator yang berhubungan atau bersentuhan dengan rotor, sehingga tidak membutuhkan komutator dan sikat arang. Karena itu penggunaan motor DC pada industri-industri mulai tergeser oleh motor induksi. Kelebihan dari motor induksi adalah konstruksinya sederhana dan kokoh, harganya relatif murah serta perawatannya mudah. Akan tetapi dalam hal pengaturan kecepatan dan torsi motor induksi bukanlah suatu hal yang mudah, karena karakteristiknya yang bersifat nonlinear dan terdapat parameter yang nilainya bersifat tidak pasti, seperti teperaturedependent, rotor resistance, fluks magnetik, koefisien gesek dan beban yang berubah-ubah $(2,3)$. 
Metode kontrol kecepatan yang biasa diterapkan pada motor induksi secara umum dapat dilakukan dengan cara, yaitu; (1) merubah banyaknya kutub, (2) mengubah tahanan luar, (3) mengubah tegangan jala-jala, dan (4) mengubah frekuensi jala-jala ${ }^{(4-6)}$. Metode perubahan kecepatan putaran motor induksi dengan mengubah banyaknya kutub sulit untuk dilakukan karena metode ini berkaitan dengan perubahan konstruksi motor dan bersifat tidak variabel. Metode perubahan tahanan luar juga dapat dilakukan untuk mengatur kecepatan motor induksi, metode ini tidak mempengaruhi konstruksi motor akan tetapi bersifat mekanik dan dipasang diluar konstruksi motor induksi, sehingga memiliki live time rendah. Metode perubahan tegangan jala-jala sangat berpengaruh terhadap torsi, karena torsi merupakan fungsi tegangan. Torsi yang dihasilkan suatu motor induksi besarnya sebanding dengan pangkat dua tegangan yang diberikan pada terminal-terminal primernya. Perubahan tegangan jala-jala juga berdampak panas pada lilitan stator ${ }^{(5)}$.

Perubahan frekuensi jala-jala untuk mengatur kecepatan motor induksi terbagi menjadi dua, yaitu skalar kontrol dan vektor kontrol. Keunggulan vektor kontrol adalah motor induksi dapat dikontrol seperti motor DC eksitasi terpisah sehingga memungkinkan pengontrolan variabel secara terpisah. Dalam hal ini variabel yang dimaksud ialah fluks dan torsi. Kompleksnya keunggulan yang ditawarkan vektor kontrol berbanding lurus dengan sulitnya penerapan dan implementasi metode tersebut pada motor induksi.
Sedangkan keuntunggan skalar vektor adalah memiliki struktur kendali yang sederhana, mudah dan cepat diprogram serta dapat dioperasikan dengan kendali loop terbuka, sehingga secara ekonomis lebih murah $^{(2,3,7,8)}$.

Penelitian ini melakukan pengaturan kecepatan putaran motor induksi dengan mengatur frekuensi jala-jala menggunakan metode pengkodekan sinyal analog menjadi durasi lebar pulsa yang mempunyai logika high dan low, atau biasa disebut dengan variabel speed drive atau inverter. Dengan tujuan menghasilkan peralatan yang dapat dipakai untuk megatur kecepatan putar motor induksi 3 fasa dengan range putaran yang lebar dan disertai perubahan putaran yang smooth.

\section{METODE}

Sebelum masuk pada metode penelitian akan dijelaskan dasar motor induksi 3 fasa, hubungan antara kecepatan, torsi serta frekuensi, dan inverter sebagai media untuk melakukan pengaturan skalar. Motor induksi merupakan suatu motor yang dicatu oleh arus AC pada statornya secara langsung dan pada rotornya dengan imbas atau induksi dari stator. Ada juga yang berpendapat bahwa motor induksi merupakan motor arus AC yang paling luas digunakan. Penamaannya berasal dari kenyataan bahwa arus rotor motor diperoleh dari arus yang terinduksi sebagai akibat adanya perbedan relatif antara putaran rotor dengan medan putar (rotating magnetic field) yang dihasilkan oleh arus stator ${ }^{(6)}$.

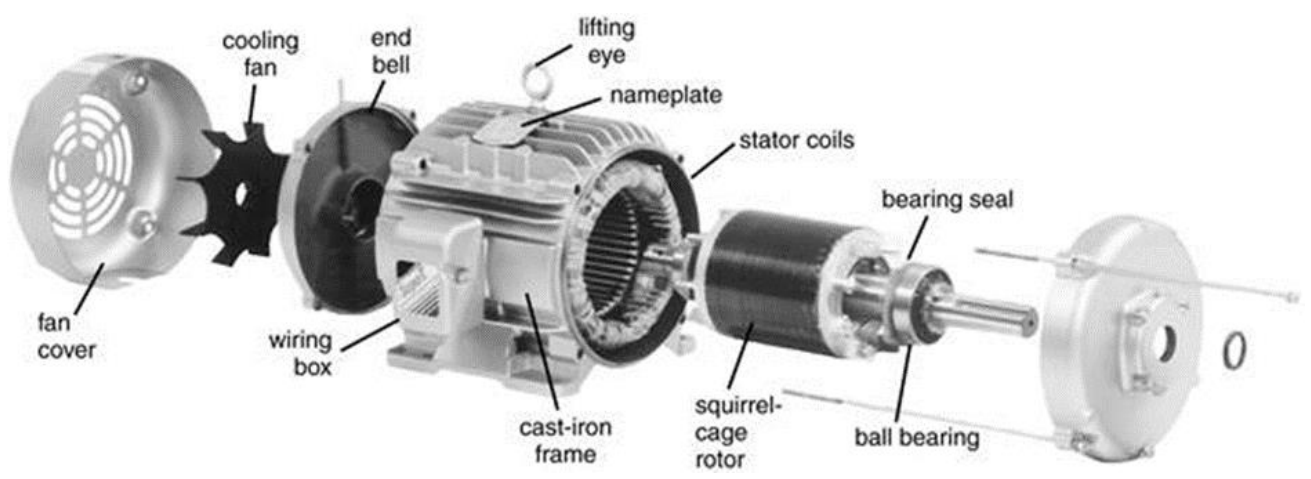

Gambar 1. Konstruksi motor induksi ${ }^{(9)}$ 
Berdasarkan dua pernyataan diatas dapat dikatakan bahwa motor induksi adalah motor arus AC dengan statornya dicatu langsung dari sumber tegangan $\mathrm{AC}$ dan arus rotornya merupakan imbas atau induksi dari statornya. Imbas tersebut sebagai akibat adanya perbedaan relatif antara putaran rotor dengan medan putar. Oleh karena itu motor AC dikenal dengan sebutan motor induksi. Sedangkan yang dimaksud dengan motor induksi tiga fasa adalah motor induksi yang pada belitan statornya dicatu dengan sumber tegangan tiga fasa yang masing-masing fasa memilki beda fasa sebesar $120^{\circ(6)}$.

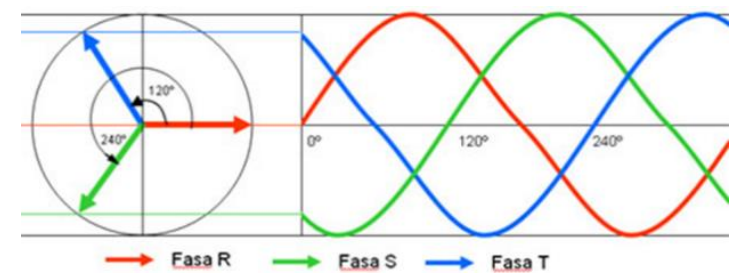

Gambar 2. Beda fasa $120^{\circ}$

Kecepatan putaran medan magnet motor induksi akan dipengaruhi oleh frekuensi sumber yang masuk ke motor (juga mempengaruhi kecepatan perputaran rotor pada motor) dengan mengacu ke Persamaan (1) berikut $^{(9,10)}$.

$$
n_{s}=\frac{120 f}{p}
$$

dengan $n_{s}$ kecepatan medan dari stator (rpm), $f$ frekuensi listrik sistem (Hz), dan $p$ jumlah kutub. Tegangan induksi timbul karena terpotongnya batang konduktor (rotor) oleh medan putar stator. Artinya agar tegangan terinduksi diperlukan adanya perbedaan relatif antara kecepatan medan putar stator $\left(\mathrm{n}_{\mathrm{s}}\right)$ dengan kecepatan berputar rotor $\left(\mathrm{n}_{\mathrm{r}}\right)$. Perbedaan kecepatan antara $\mathrm{n}_{\mathrm{s}}$ dan $\mathrm{n}_{\mathrm{r}}$ disebut slip (S) yang dinyatakan dalam Persamaan (2).

$$
S=\frac{n_{s}-n_{r}}{n_{s}} \times 100 \%
$$

bila $n_{r}=n_{s}$, tegangan tidak akan terinduksi dan arus tidak mengalir pada kumparan jangkar rotor, dengan demikian tidak dihasilkan kopel. Kopel motor akan ditimbulkan apabila $\mathrm{n}_{\mathrm{r}}$ lebih kecil dari $\mathrm{n}_{\mathrm{s} .}$ Dilihat dari cara kerjanya, motor induksi disebut juga sebagai motor asinkron $(2,6,9,10)$

Bardasarkan rumus $P_{m}=\omega T$ jika daya mekanik $\left(P_{m}\right)$ dianggap konstan maka besarnya torsi tergantung dari kecepatan sudut ( $\omega)$. Jika putaran rotor dipercepat, maka torsi yang dihasilkan kecil, sedangkan jika torsinya besar maka kecepatannya lambat. Gambar 3 menggambarkan hubungan antara kecepatan dengan torsi. Pada beban penuh motor berputar pada kecepatan Nn. Pada saat beban mekanik meningkat, kecepatan motor menurun sampai torsi maksimum sama dengan torsi beban. Bila torsi beban melebihi Tm, maka motor akan berhenti ${ }^{(6)}$.

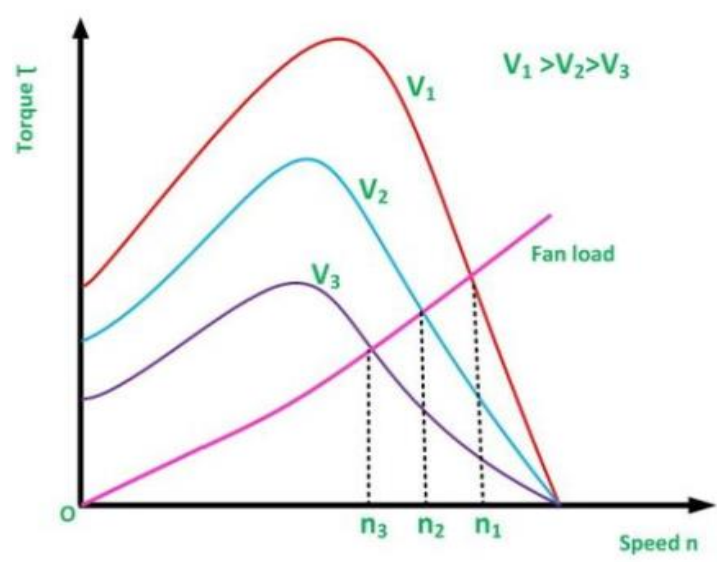

Gambar 3. Kurva kecepatan terhadap torsi ${ }^{(4)}$

Kecepatan sinkron motor induksi tergantung pada frekuensi input. Untuk menjaga agar konstan, maka tegangan dan frekuensi input tervariasi sama dan sebanding. Jika frekuensi dibuat dua kali, maka frekuensi juga dibuat dua kali. Jika frekuensi dan tegangan input dinaikkan, maka kecepatan putar motor akan semakin cepat ${ }^{(6)}$.

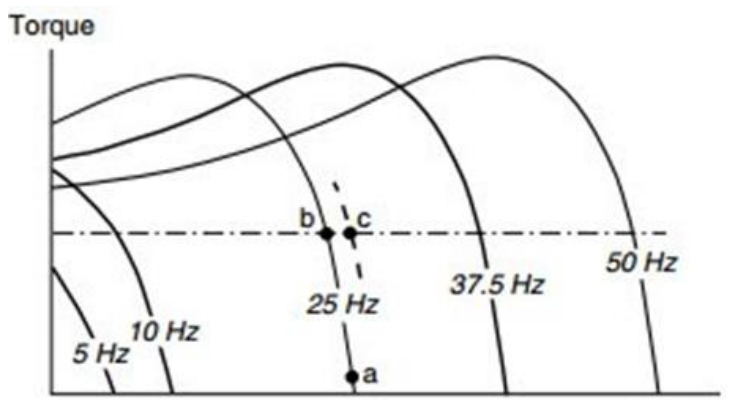

Gambar 4. Kurva frekuensi terhadap torsi ${ }^{(6)}$ 
Kecepatan putaran motor induksi merupakan fungsi dari torsi elektromagnetik dan torsi beban. Adapun persamaan untuk mendapatkan kecepatan motor induksi adalah sebagai berikut ${ }^{(1)}$ :

$$
\frac{J}{P} \frac{d}{d t} \omega_{r}+B \omega_{r}=T_{e}-T_{L}
$$

dengan $\mathrm{T}_{\mathrm{L}}$ torsi beban, $\mathrm{T}_{\mathrm{e}}$ torsi elektromagnetik, J momen inersia, p jumlah pasang kutub, $\omega_{\mathrm{r}}$ kecepatan angular rotor, dan $\theta_{\mathrm{r}}$ posisi sudut.

\section{$-5 \mathrm{~V} d \mathrm{c}$}

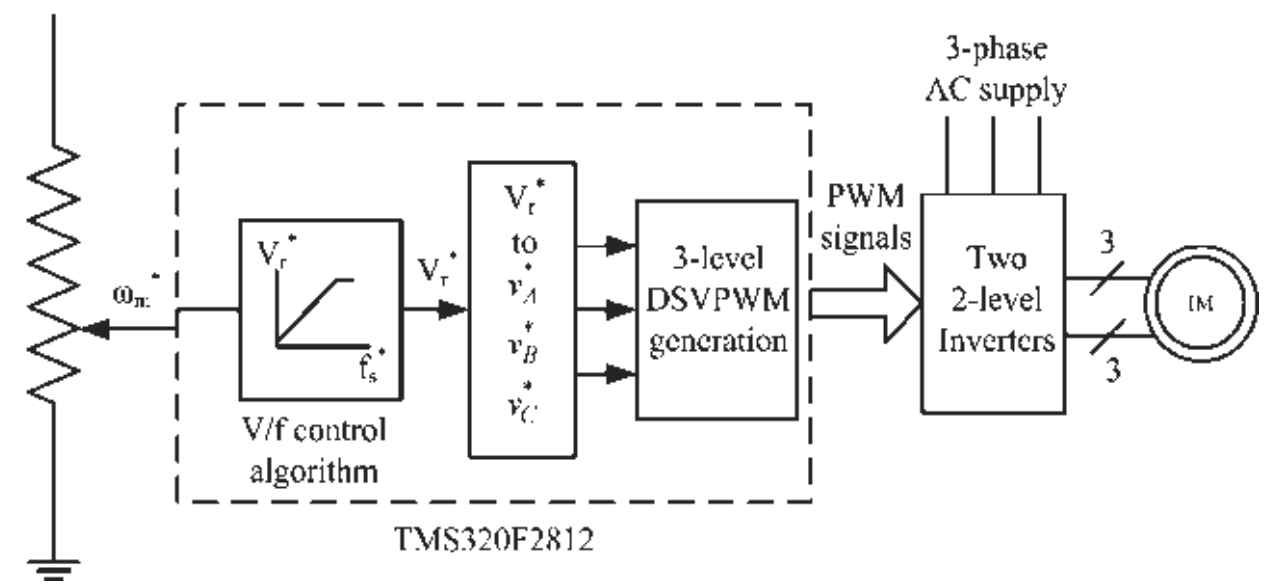

Gambar 7. Desain inverter 3 fasa

Inverter 3 fasa merupakan alat yang didesain untuk mengkoversi tegangan DC ke AC dengan frekuensi keluaran dapat diatur. Inverter 3 fasa dapat dibuat dengan menggunakan komponen transistor, thyristor, MOSFET, IGBT dan lain-lain. Pada penelitian ini digunakan 6 MOSFET dalam pembuatan inverter 3 fasa. Sebagaimana terlihat pada Gambar $5^{(1,11)}$.

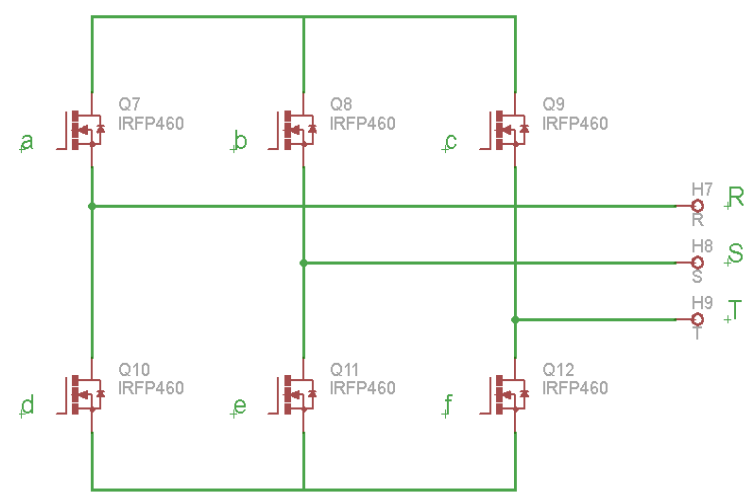

Gambar 5. Inverter 3 fasa

Setiap transistor akan menghantarkan selama $120^{\circ}, 3$ buah transistor dalam keadaan on setiap $1 / 2$ siklus. Ketika transistor a on maka terminal $\mathrm{R}$ akan terhubung dengan terminal positif tegangan masukan. Ketika transistor d on maka terminal $\mathrm{R}$ akan terhubung dengan terminal negatif dari sumber.

Ada 6 buah mode operasi untuk penyalaannya dalam 1 siklus dan dengan jarak durasi setiap pengoperasiannya adalah $60^{\circ}$. Bentuk gelombang keluaran penyalaan transistor dengan six step square wave $120^{\circ}$ terlihat pada Gambar 6 dibawah ini.

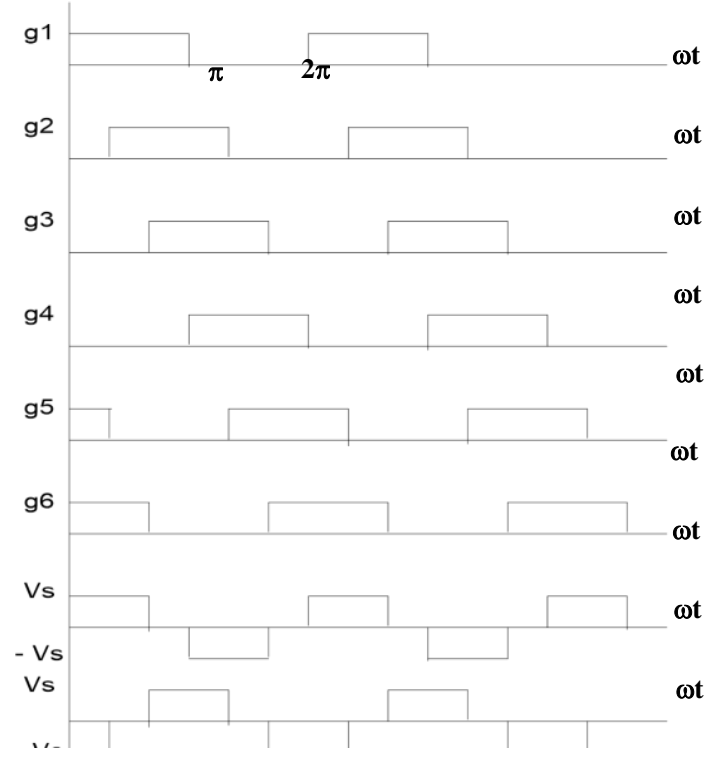

Gambar 6. Bentuk gelombang penyalaan $120^{\circ}$ 
Motor induksi yang digunakan untuk penelitian ini adalah motor induksi 3 fasa mini hubungan delta, berikut ini adalah tabel parameter motor induksi 3 fasa yang digunakan.

Tabel 1. Parameter motor induksi 3 fasa

\begin{tabular}{cll}
\hline No. & \multicolumn{1}{c}{ Parameter } & \multicolumn{1}{c}{ Nilai } \\
\hline 1. & Jenis motor & 3 fasa \\
2. & Tipe & EM-3330-3C \\
3. & Kecepatan medan putar & $1420 / 1670 \mathrm{RPM}$ \\
4. & Frekuensi & $50 / 60 \mathrm{~Hz}$ \\
5. & Arus & $1,4 \mathrm{Ampere}$ \\
6. & Daya & $0.3 \mathrm{KW}$ \\
7. & Tegangan & $\Delta 220 \mathrm{VAC}$ \\
\hline
\end{tabular}

\section{HASIL DAN PEMBAHASAN}

Pada penelitian ini dilakukan dua jenis pengujian, yaitu pengujian kinerja inverter 3 fasa dan pengujian sistem secara keseluruhan. Implementasi hasil desain inverter 3 fasa pada penelitian ini ditunjukkan Gambar 8. Inverter tersebut menggunakan 6 buah MOSFET tipe IRFP460 sebagai penguat akhir. Sedangkan untuk frekuensi dibangkitkan dengan mikrokontroler tipe ATMEGA 8535.

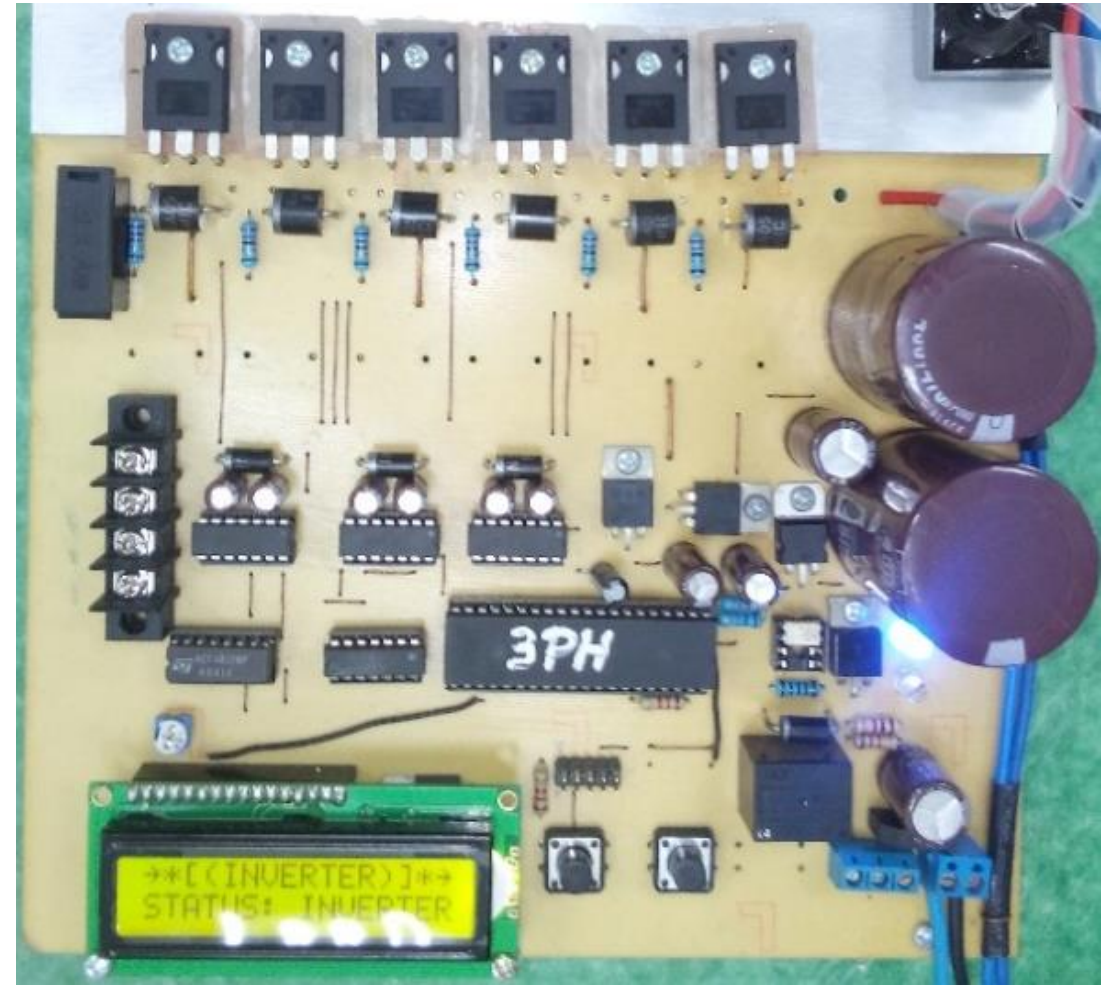

Gambar 8. Inverter 3 fasa

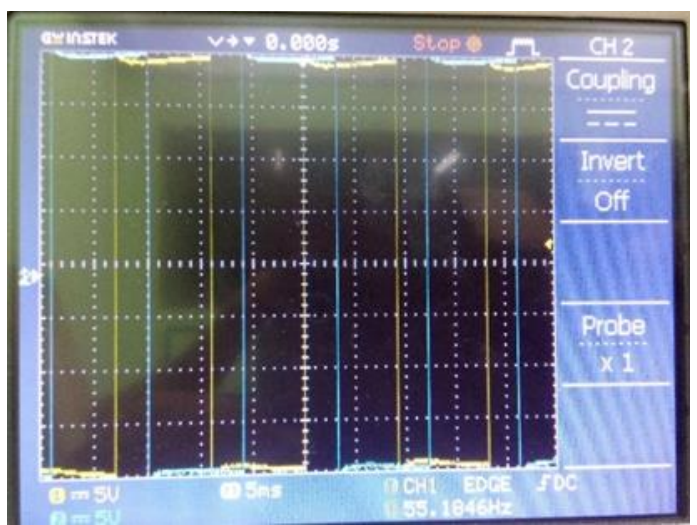

Gambar 9. Keluaran fasa R dan S ke netral
Hasil pengujian menunjukkan inverter 3 fasa dapat berkerja dengan baik, sebagaimana ditunjukkan pada Gambar 9. Gambar tersebut memperlihatkan keluaran fasa $\mathrm{R}$ dan fasa $\mathrm{S}$ terhadap netral dengan beda sudut $120^{\circ}$, frekuensi $50 \mathrm{~Hz}$ dan duty cycle 50\%.

Dari hasil pengujian yang telah dilakukan dengan menvariasikan frekuensi sumber yang masuk ke motor induksi 3-fasa melalui inverter dengan kondisi tidak ada beban dan tegangan sumber konstan, maka 
diperloleh hasil kinerja motor seperti yang diperlihatkan pada Gambar 10 dan Gambar 11.

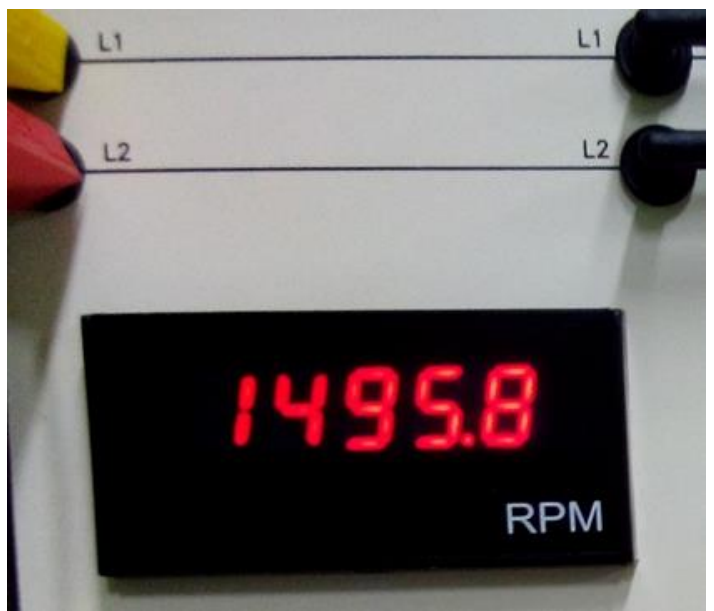

Gambar 10. Hasil pengukuran arus dengan $f$ $50 \mathrm{~Hz}$

Dengan memperhatikan Tabel 2 terlihat bahwa dengan memperbesar nilai frekuensi akan menaiikkan kecepatan putar motor induksi, begitu juga dengan sebaliknya atau dapat dikatakan kecepatan dan frekuensi berbanding lurus. Akan tetapi mengubah frekuensi sumber harus mengikuti aturannya, sebagaiman tertulis dalam penelitian Anthony Zuriman.

Tabel 2. Hasil pengukuran kecepatan motor induksi

\begin{tabular}{ccc}
\hline No. & $\begin{array}{c}\text { Frekuensi } \\
(\mathrm{Hz})\end{array}$ & Kecepatan (RPM) \\
\hline 1 & 50 & 1495,8 \\
2 & 55 & 1642,8 \\
3 & 60 & 1794,6 \\
4 & 65 & 1943,4 \\
5 & 70 & 2090,4 \\
\hline
\end{tabular}

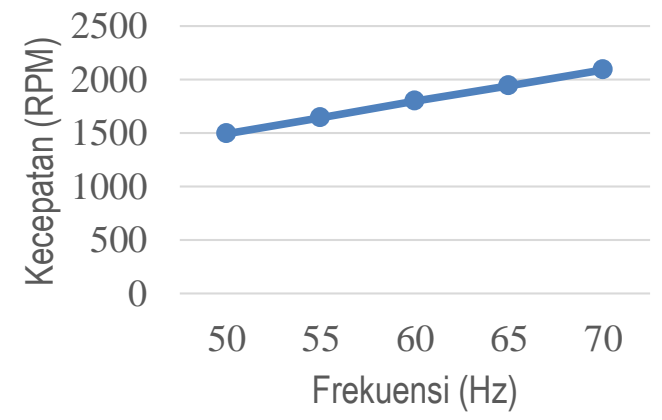

Gambar 11. Respon frekuensi terhadap kecepatan
Gambar 11 yang memperlihatkan sajian dalam bentuk kurva dapat mempermudah analisa Tabel 2.

\section{SIMPULAN}

Berdasarkan hasil penelitian yang telah dilakukan dapat diambil kesimpulan sebagai berikut: (1) Peralatan yang dibuat dapat berfungsi dengan baik yang ditunjukkan dengan perubahan frekuensi dapat mengatur kecepatan motor induksi; (2) Memperbesar frekuensi jala-jala dapat menaikkan kecepatan motor induksi fasa, pada penelitian ini dengan frekuensi $70 \mathrm{~Hz}$ didapatkan kecepatan 2090.4 rpm; (3) Memperkecil frekuensi jala-jala dapat menurukan kecepatan motor induksi fasa, pada penelitian ini dengan frekuensi $50 \mathrm{~Hz}$ didapatkan kecepatan $1495.8 \mathrm{rpm}$; (4) Perubahan frekuensi sumber juga dapat menyebabkan perubahan unjuk kerja motor; dan (5) Perubahan putaran motor bisa benarbenar diubah dengan smooth.

\section{REFERENSI}

[1] E. Wahjono. Pengaturan Kecepatan Motor Induksi Sebagai Penggerak Mobil Listrik Dengan Kontroler Fuzzy Logic Berbasis Direct Torque Control. Jurnal Ilmiah Mikrotek, 1(3), 136-144, 2013.

[2] H. D. Desai \& D. Bhanabhagvanwala. Comparative Analysis Between Scalar Control And Direct Torque Control Methods For Induction Motor Drives. International Journal of Current Engineering and Scientific Research (IJCESR), 2(7), 38-43, 2015.

[3] P. B. Kumar, M. B. Kumar \& A. S. Kumar. Comparative Analysis of scalar \& vector control of Induction motor through Modeling \& Simulation. International Journal of Innovative Research In Electrical, Electronics, Instrumentation And Control Engineering. 2(4), 1340-1344, 2014.

[4] N. Gurle, T. Sheikh, A. Kumari \& R. Argelwar. Speed Control of Three Phase Induction Motor by Stator Voltage 
Control. Journal of Network Communications and Emerging Technologies, 6(4), 307-312, 2016.

[5] Fauzan \& Zamzami. Pengaturan Kecepatan Motor Induksi Satu Phasa Dengan Menggunakan Sakelar Pemulih Energi Magnetik. Jurnal Teknologi, 13(12), 29-33, 2013.

[6] Isdiyarto. Dampak Perubahan Putaran Terhadap Unjuk Kerja Motor Induksi 3 Phasa Jenis Rotor Sangkar. Jurnal Kompetensi Teknik, 1(2), 57-64, 2010.

[7] H. Akroum, M. Kidouche \& A. Aibeche. Scalar Control of Induction Motor Drives Using dSPACE DS1104. International Conference on Systems, Control and Informatics, 2013.

[8] P. K. Behera, M. K. Behera \& A. K. Sahoo. Speed Control of Induction Motor using Scalar Control Technique. International Conference on Emergent Trends in Computing and Communication. 2014.
[9] Z. Anthony. Pengaruh Perubahan Frekuensi Dalam Sistem Pengendalian Kecepatan Motor Induksi 3-Fasa Terhadap Efisiensi Dan Arus Kumparan Motor. Jurnal Teknik Elektro ITP, 1(1), 25-29, 2011.

[10] Slamet \& F. Yusivar. Perancangan Rangkaian Kontrol Kecepatan Motor Induksi Ac Tiga Phasa Menggunakan Metode Space Vector Dan Kendali V/F Konstan Berbasis Microcontroller AVR Tipe ATMEGA1. Seminar Ilmiah Nasional Komputer dan Sistem Intelijen, Depok, 2008.

[11] D. S. A. Pambudi, M. Sarwoko \& E. Kurniawan. Kontrol kecepatan motor induksi tiga fasa Menggunakan tegangan dan frekuensi Dengan modulasi vektor ruang. Jurnal Penelitian dan Pengembangan Telekomunikasi, Kendali, Komputer, Elektrik, dan Elektronika (TEKTRIKA), 1(1), 76-84, 2016. 